\title{
The Limitations of Reading to Young Children in Literary Arabic: The Unspoken Struggle with Arabic Diglossia
}

\author{
Riham Shendy \\ World Bank, Washington DC, USA; \\ European University Institute, Florence, Italy
}

\begin{abstract}
This interdisciplinary paper draws on findings from academic research on Arabic language diglossia demonstrating the linguistic distance between spoken Arabic, a'amiya and written Arabic, fusHa. It extends the implications of these findings to the literature on child development and reading. In this respect, it is is the first study to address the challenges of reading to children in a language diglossia situation. The paper starts by addressing the unfounded popular claim that fus $\mathrm{Ha}$ and $\mathrm{a}$ 'amiya are similar. It then outlines relevant practices from developed countries that feature language diglossia and finds no merit in the second popular concern that reading to children in their mother-tongue - a'amiya - would weaken their later grasp of fusHa - the language of education. The common practice of ad hoc on-the-spot translation of fusHa text in storybooks to a'amiya is not optimal for reasons highlighted. Further, the paper discusses the wider proven benefits of reading to children that go beyond literacy, and that are likely forgone by the exclusive focus on producing and reading children's books in only fus $\mathrm{Ha}$. Finally, the study argues that the sociolinguistic nature of a'amiya and the demographics of most Arab countries ought to support a viable market for a'amiya children's books.
\end{abstract}

Index Terms-Arabic diglossia, read-aloud, mother-tongue, second dialect, child development, children literature

\section{INTRODUCTION}

When adults read for pleasure, they expect to enjoy the experience: to immerse themselves in the narrative and free their imagination. Enriching their vocabulary and enhancing their language skills, are certainly byproducts of the reading experience but seldom are the primary objective of leisure reading. Story reading to young children need not be any different.

Reading aloud to children promotes their love for books and provides treasured time together with a parent. The tradition has an indisputable role in building literacy, but it should not detract from a child's enjoyment of a good book. Ample research has shown that the benefits of reading aloud to young children extend far beyond developing their literacy skills. As will be discussed, reading to children has a rich role in enhancing their emotional, social, and cognitive development.

In the Arabic-speaking world, however, these key aspects of reading to children that extend beyond literacy tend to be overlooked. One primary objective of reading aloud in Arabic is to develop and enhance children's literacy skills. Fantasy, enjoyment, and attaining the wider benefits of reading become secondary objectives. Largely responsible for this intense focus on reading aloud for literacy is a difference between the spoken and written Arabic language, a situation referred to as language diglossia.

\section{Diglossia IN THE ARabic Language}

Language diglossia, introduced in Ferguson 1959, entails a strict functional differentiation of two varieties of the same language used in different domains and for distinct purposes. The colloquial (vernacular) variety is learned at home and used in informal contexts, while the standard or literary variety is learned in school and used in formal settings.

Arabic is a typical case of language diglossia, in which speakers within a single community (nation) simultaneously use two varieties of Arabic - one for everyday communication and the other for writing and formal interactions. The spoken (vernacular) Arabic is known as a'amiya. It is the language used in all oral communications: at home, at work, and in the streets. Most TV talk shows, movies, songs and soap-operas are in a'amiya Arabic. Children grow up speaking a'amiya for everyday speech at home and in their neighborhoods. A'amiya is not socially stigmatized and is not commonly related to social class. It is the default language spoken by all segments of an Arab country's population, including politicians, university professors, physicians...etc. However, a'amiya is usually stigmatized as a literary form.

The official and more formal Arabic is known as Modern Standard Arabic (MSA), or fusHa. It is based on the language of the Quran, the Holy Book of Islam. FusHa is used for literary and scholarly reading and writing, Its oral 
use is confined to few formal interactions, such as political speeches and religious sermons. FusHa is uniform across the Arabic-speaking world, while dialects of $a$ 'amiya differ across nationality-based Arabic speaking communities. In this dichotomy, a child's mother-tongue and hence earliest speech is a'amiya Arabic whilst literacy is based on fusHa, which is acquired only at school age and in the classroom setting - through instruction not immersion. Thus children acquire fus $\mathrm{Ha}$ Arabic only with conscious effort. In this respect it is no one's mother-tongue.

\section{The Limitations of Translating Fusha TEXT WHEn REAding to CHILDREN}

Like other Arabic literature, children's books in the Arab world are written almost exclusively in fusHa Arabic, the language that the child will only master after several years of schooling. This reality, in which young children do not immediately understand the written language, requires parents who read aloud to resort to one of two techniques. The first is to read the fusHa text and follow with translation into the spoken a'amiya that the child comprehends. In employing this practice, a significant part of reading time is spent on defining and explaining unfamiliar words. Parents who prefer simply to tell a story use a second technique. They tend to skip reading the fusHa text altogether and resort to on-the-spot translation directly into a'amiya. Indeed, orally translating storybooks to children from a foreign language to their mother-tongue is an accepted practice. However, it is usually not the only mode of reading to children - as is the case in the Arabic speaking world. Although, the reader's regular and immediate translation of fusHa books into a'amiya may seem a sufficient solution, it is far from optimal.

First, young children love repetition and enjoy hearing the same familiar book multiple times. Part of what they enjoy is the predictability of the text. Children who are read to regularly race to complete sentences as a storybook is read to them over and over. Repeatedly listening to the same storybooks has advantages. A study of language acquisition looked at two groups of children. Compared with children who usually heard different stories, those who were repeatedly read the same stories showed a dramatic increase in their ability both to recall and to retain new vocabulary (Horst, Parsons and Bryan, 2011). On-the-spot translation takes away from this familiarity and predictability. The reader makes up the text every time, changing wording and phrases, and even dropping details altogether.

Second, because simultaneously reading and translating text involves considerable effort, the reader is somewhat discouraged from regularly reading and is likely to be less present for other important parts of the experience. Research demonstrates that the most effective read-aloud practices are those in which the child is actively involved-asking and answering questions rather than passively listening. Effective read-aloud techniques should include elements such as: analytical talk between reader and child: making predictions, discussing the characters' motivations, connecting events from different parts of the story, and discussing the illustrations. (Lane and Wright, 2007; McGee and Schickedanz, 2007).

Finally, translating on-the-spot does not support reading books of rhymes. Such books have long existed in the international children's literature and are becoming increasingly popular for younger children. Widely read examples span early books by Dr. Seuss - e.g., Fox in Sox, The Cat in the Hat, Oh, the Places You'll Go, to more recent ones, such as the popular books by the British Children's Laureate, Julia Donaldson-e.g., Gruffalo, Room on the Broom, The Smartest Giant in Town. In addition to being fun to listen to, rhyming books, like nursery rhymes, enhance children's phonological awareness. This refers to understanding the sound structure of language - a knowledge that initially takes form in oral language. Notably, phonological awareness is a strong predictor of a child's early literacy development (Bryant, et al., 1989, 1990; MacLean et al., 1987; Trehearne, 2003; Melby-Lervag et al., 2012). Interpreting and translating a text written in fusHa rhymes into the colloquial spoken language cannot help but alter wording and sentence structure. The reader therefore cannot maintain the original rhyme, and consequently negates a key purpose of the book.

\section{The CURRENT MARKET OF ARABIC CHILDREN's BOOKS}

The question then arises as to why no children's books are published in a'amiya, particularly for young children? The only exceptions to disdaining a'amiya books for children are works of heritage and folk songs. They are similar to those by Helmy El Touney, published by Dar El Shorouk; YaHya Abu El Fassad; Baba Gai Imta; and Kan Fi WaHda Sit. Admittedly, there are independent efforts to publish children's books in a'amiya. However, writers of these works have had to produce their books apart from the mainstream children's book market and resort to self-publishing. Massmarket publishers are reluctant to support this genre of colloquial books. Consequently, their penetration is slow and limited. Notably, the Middle Eastern book market mainly distributes and sells its books through traditional channels. Book fairs and exhibitions, bookstores, and libraries are their primary sales outlets (Rand, 2009). These longestablished networks give large publishers an advantage, particularly given that Internet publishing, distribution, and sales in the Arab region are still at their infancy.

Interestingly, writing in a'amiya for adults has long existed and is endorsed by many of the same big publishers who are averse to a'amiya books for children. For instance, in Egypt the first novel written entirely in Egyptian $a$ 'amiya was released in 1966, namely Kantara Who Disbelieved by Mustafa Musharafa (El-Wardani 2012). In the recent years a'amiya adult books have become more and more common, with many books becoming best sellers. This practice of publishing books in a'amiya only for adults demonstrates contradictory standards, where a'amiya books are accepted 
for adults — who in fact know fusHa — while they are rejected for young children — who indeed are not yet familiar with that language/dialect.

\section{CONCERnS OVER WRITING CHILDREN LITERATURE IN A 'AMIYA ARABIC}

Suggestions to develop children's literature in a'amiya have generally been met by either of two adverse reactions from publishers, authors, and parents. The first rests on the popular belief that fusHa and a'amiya do not significantly differ from one another. The second is the common concern that such an initiative would weaken Arab children's later command of fusHa - the official language; the language of education, literature, most written communication; and the language of Islam and pan-Arabism.

Despite the widespread popular perception that fusHa and a'amiya are very similar, a clear consensus in the academic literature maintains that a significant disparity exists between both languages codes. As several linguists have put it, "The difference between these two language codes manifests itself in several linguistic domains: lexicon, phonology, syntax and grammar" (Eviatar and Ibrahim, 2014; Maamouri, 1998; Schiff and Saiegh-Haddad, 2018; Ibrahim et al., 2005; Myhill, 2014; Saiegh-Haddad and Spolsky, 2014; Siegel, 2010; Khamis-Dakwar, 2005).

For example, comparing Egyptian a'amiya Arabic and fusHa demonstrates some of these technical differences in practical terms. Similar comparisons can be made using a'amiya dialects of other Arab countries. First, a number of words that may sound similar in fus $\mathrm{Ha}$ and a'amiya do not completely phonologically overlap. For example, words like monkey, snake, and darkness are, respectively, ird, te'ban and dalma in a'amiya versus kird, tho'ban and zalam in fusHa. Another set of words significantly or completely change phonological form in fusHa. Phrases such as I want and I am joking are ana a'awiz and ana bahaazar in a'amiya, compared with ana o'reed and ana amzah in fusHa. Words like mouth and early, which in a'amiya are bo' and badry, are completely altered to fam and bakir in fusHa. In some cases, common a'amiya words still exist in fusHa but carry completely different meanings. The word for car in the a'amiya dialect, for example, is a'arabiya, which in fusHa means Arabic; the fusHa word for car is sayarrah. Similarly, the word for letter (missive) is gawab in a'amiya, which means reply in fusHa; the fusHa word for letter is khitab. Further illustrations of the linguistic distance between fus $\mathrm{Ha}$ and a'amiya, including changes in sentence structure, can be seen in Saiegh-Haddad, 2002.

Understandably, these differences between the two language codes may seem insignificant or unimportant to adults who have had years of schooling in fusHa. The extent of the difference might perhaps be best portrayed by informally testing comprehension of fusHa in a native Arab who is illiterate thus has not formally learnt fusHa, or, alternatively, testing comprehension of a'amiya in non-native Arabic speakers who have learnt Arabic as a foreign language, commonly in fusHa. For both, the struggle is to understand and communicate in the language code to which they have not been exposed. This difference would similarly be profound from a child's perspective. Consequently, reading in fusHa, for example in the intimate setting of a bedtime story, strips familiarity and pleasure from the experience, making it more instructional than leisurely.

The linguistic distance between the two language codes has been measured in academic and empirical research in linguistics. In Schiff and Haddad (2018), the authors summarize a study that quantifies the difference between Palestinian a'amiya and fusHa. The study recorded five-year-old children on a typical kindergarten day as they interacted with each other in a'amiya. Researchers collected about 4,500 different word types that were analyzed and compared with words in fusHa. Their analysis showed that only about twenty percent of the words in the children's spoken Arabic were identical across both language codes. Forty percent had overlapping phonological forms in $a$ 'amiya and fusHa - similar to kird versus ird for monkey. The other forty percent were completely different, with unique forms in fusHa compared with their a 'amiya counterparts, similar to fam in fusHa versus bo' in a'amiya, both for the word mouth. Similar quantitative studies have not been found for Egyptian a'amiya or for other colloquial Arabic dialects, however a general inference can be made from this Palestinian study.

On one side of this debate on the extent of the difference between fusHa and a'amiya, research has shown that children being taught fusHa compare more with those learning a second language than with those merely learning a formal variation of a'amiya. The two languages retain their status as first and second languages in the cognitive system (Ibrahim and Eviatar, 2009; Ibrahim \& Aharon-Peretz 2005 \& Ibrahim 2000). On the other side of this debate, Albirini (2016) discusses that fusHa should not be considered a second language; Arab children are exposed to it during early stages of their language development via cartoons, news, and children's books. Consequently, these children have receptive skills in fusHa. His conclusion is that the situation of Arab children is similar to that of passive bilingualism, in which children speak one language and can understand another, but do not speak it.

Promulgating whether fusHa is a second language or merely a dialect is beyond the scope of this paper. The intention of the above discussion is to simply present an overview of the perceived versus actual difference between $a$ 'amiya and fusHa. Although for many Arabs both codes are popularly considered "the same language," it seems fair to assume that a majority would agree that only a'amiya Arabic is an Arab child's mother-tongue. That is to say, it is Arab children's first language, the language learned at home, and the language of communication in their immediate environment and within their community.

The second common concern about a'amiya books - that they would weaken children's subsequent command of fus $\mathrm{Ha}$ - can be answered by examining other communities with language diglossia. Switzerland provides another 
classic example. The official language in the German-speaking part of the country is High German (Hochdeutsch), which is the same standard German spoken in Germany. The spoken language is Swiss German (Schweizerdeutsch), a dialect distinct from High German. Germany itself is another example of diglossia, where High German is the official language, but various regions speak several different dialects. In Scotland, indigenous English dialects differ considerably from Standard English. Several other languages are also spoken in Scottish communities.

In these examples and in many others, books for young children are available in the local spoken dialect alongside books in the official language. Both are frequently used in nurseries and preschools. Books in official and colloquial languages are displayed side by side in bookstores, sold on the Internet, and available in public libraries. Publishers in one region will publish a book in both spoken and written dialects, whereas in another region publishers will do one or the other-publish either in the formal language or in the spoken local dialect. For example, Beltz and Gelberg published the popular children's storybook, The Gruffalo, in spoken Swiss German, the Schwäbisch dialect, in addition to official High German. From Germany, another example is the children's book, Guess How Much I Love You, which was translated by the publisher Fischer Sauerländer into High German, in addition to various spoken German dialectsFränkischer, Schwäbisch, and Bairische. Differently in the United Kingdom, MacMillan published The Gruffalo in Standard English, whereas Black and White Publishing published it in five spoken Scottish dialects-Glaswegian, Doric, Dundonian, Orkney Scots, and Shetland Scots, and the publisher Dref Wen published The Gruffalo in Welsh.

Two key takeaways emerge from these countries' practices. First, these regions do not debate or question whether reading to children in their native dialects constrains their later grasp of the official language of the country and that of education. Second, these cases reflect the experience of developed countries with high, if not full, literacy levelssuggesting that reading to young children in their spoken mother-tongue does not risk their subsequent literacy acquisition.

Although the experiences of these diglossic countries and regions can directly translate to the Arab world, one distinction is worth noting. In these countries, the official language is a "living language" e.g., English in Scotland is the mother-tongue language in most regions of the United Kingdom, and High German in Switzerland is the mother-tongue language in most areas of Germany. In this respect, the official language in Scotland and Switzerland cannot compare with fusHa. While fusHa is certainly the official language of the Arab world, it is no one's mother-tongue. The experience of a young Arab child being read a book written in fusHa is thus necessarily more difficult and more emotionally distant.

\section{Beyond Literacy: THE WIDER Benefits OF REAding To CHILDREN}

Writing and publishing children's literature in their spoken dialects is a growing trend worldwide. It has been justified by well-established research on the benefits of reading to children as young as two years old, and reading to them in their mother-tongue. Various research, including country studies from Sweden, Norway, the Philippines and the USA, demonstrate the positive impact from employing children's mother-tongue during the early stages of their education. Using the native language was found to help transition children to the official language of education and was found to result into better scholastic attainment. (Osterberg, 1961; Siegel, 2006 and Rickford, 1998; Bull, 1990; Simpkins and Simpkins, 1977; DeGraffs, 2016; Walter and Dekker, 2001; Myhill, 2014; Mammouri, 1998, Tegegne 2015). In their numerous publications on this issue, the UNESCO has also been one of the long and strong proponents of education in the mother-tongue.

For the purposes of this discussion, however, it is critical to distinguish between the two types of children's books: the books read to a child by an adult, akin to storytelling, and the books designed for children who read independently, tailored to varied reading abilities. Generally, storybooks in colloquial dialects are intended for reading to children.

The preeminence of fus $\mathrm{Ha}$ is uncontested, and it is therefore critical to clarify that this paper does not in anyway advocate against reading to children in fusHa. Empirical studies have shown that early exposure of Arab preschool children to fusHa Arabic texts (through stories) allows for a smoother transition to the Arabic literary language (Felistine et al., 1993; Ayari, 1996; Abu Rabia, 2000). It is important, however, to note particular elements in these experiments that have led to such findings. For example, most of the fusHa storybooks used in the Felistine et al. (1993) study were specifically developed for the experiment to ensure content attractive to children. Additionally, the storybooks employed language carefully chosen to include as many words as possible that are common to both $a$ 'amiya and fusHa. In fact, the study notes that in order to include as many words as possible from a'amiya, the stories were first written colloquially; subsequently the text was carefully modified to fusHa. Further, the children in these experiments had a regular and repetitive exposure to the same stories over a long time.

In light of this discussion, professionals in the children's book industry should address the need for mother-tongue children literature, in particular for the younger age groups. The idea is to make a'amiya books available along with those in fusHa, allowing parents and caregivers to choose which they want to read and for what purpose. It should be made clear that their fear of a'amiya publications as detrimental to fusHa literacy is unfounded. Reading in fusHa for developing literacy is certainly something parents can and should do if they wish to. But that should not deny children the joy of effortlessly listening to a story in their familiar language, an experience that children around the world enjoy.

The importance of the mother-tongue in communicating knowledge to young children should not be undermined. This contention was recognized in the international children's television program, "Sesame Street". The producers of 
the program recently revised their strategy in Egypt and other Middle Eastern countries. After producing its alam simsim 2010 series in Egyptian a'amiya for the Egyptian market, they experimented in the following years and produced only iftah ya simsim in fusHa, with the aim of catering to the entire Arab region. Nonetheless, the latter's lack of broad success led to a policy reversal. A local Egyptian a'amiya sequel of alam simsim returned in 2017.

In addition to literacy, the other benefits of reading to children deserve significantly more attention. Research from the Organization for Economics Co-operation and Development (OECD 2002) shows that reading enjoyment is more important for children's educational success than their family's socioeconomic status. Further, a research overview by the National Literacy Trust in the UK highlights the many benefits of reading to children for pleasure. Reading aloud to children from a young age broadens their attention span, develops listening skills, and increases vocabulary development and language comprehension.

Reading stories to children further enhances their cognitive abilities as the child follows the story's plot and characters, and it fosters communication as stories and illustrations are discussed. During the experience of listening to a story, children broaden their imaginations beyond their own immediate milieu, experiencing other people, places, times, and events. Through a story, a child acquires factual knowledge and learns how the world works, indirectly and effortlessly (Clark and Rumbold, 2006; Mendelsohn et al., 2018; Duursma et al., 2008; Lane and Wright, 2007; Hemmati et al., 2015).

Stories can also provide an excellent means for children to develop empathy and contemplate ethical questions as they get deeply engaged with the story's characters (Nikolajeva, 2012). A relevant study was published in the April, 2018 issue of Pediatrics, the official journal of The American Academy of Pediatrics. The researchers found a positive link between parents' reading aloud to (and playing with) their children, and the children's social and emotional development. Children who experienced these activities were found to have a lower risk of developing attention problems and hyperactivity later in life.

The intended key message of this paper is to extend to young Arab children the experience of being read to in their mother-tongue, the language they already understand. At the same time, we nourish our children's love for books and develop in them positive attitudes towards reading. Children whose early encounters with literacy are enjoyable are more likely to develop a predisposition to read frequently and broadly in subsequent years. The cornerstone of lifelong reading is laid during the early years (Baker and Mackler, 1997; and Clark and Rumbod, 2006).

\section{The Business Potential FOR CHILDREN's BOOKS IN A 'AMIYA ARABIC}

From a business perspective, one can expect that publishing colloquial children's books ought to be economically feasible, given the market size of most Arab countries. For instance, countries like Egypt, Sudan, Saudi Arabia, Morocco, and Iraq each have sizable populations of more than 30 million people; Egypt alone has 97 million. These numbers support a sizable potential local market for colloquial children's books compared to the European examples. Only 5 million of the 8.5 million Swiss population speak Swiss German, scattered across different sub-dialects. In Scotland, various spoken dialects and languages exist among a total Scottish population of only 5 million. Parts of the German population of 83 million speak various regional dialects.

In comparison, the same a'amiya dialect is spoken by almost all segments and classes of an Arab country's population. This leaves less room for political concerns regarding national fragmentation (e.g. the Catalan, Basque and Galician languages/dialects in parts of Spain compared to the official Spanish language) or social concerns regarding elevating the status of a spoken dialect that is commonly associated with an underprivileged communities or social class (e.g. the ebonics dialect in the United States when compared to the standard English language, or French Creole in Haiti when compared to standard french, the country's official language). Moreover, the Arab countries have the additional advantage of a young population with, on average, more than 25 percent under the age of 14 years, compared with an average of only 15 percent in the European examples. (WDI Data, 2017).

Admittedly, despite Arab nations' large populations, book production and reader consumption are both relatively low, compared with other regions with similar socioeconomic development levels (Schwartz et al., 2009; Martin et al., 2017). A new index, the Arab Reading Index 2016 (ARI), was recently developed and produced by the United Nations Development Programme (UNDP), in collaboration with the Mohammed Bin Rashid Al Maktoum Foundation (MBRF). According to the Index, reading levels in Arab countries are notably higher than the often repeated assertion that "Arabs read six minutes a year on average". The report shows the latter to be a myth lacking statistical evidence and any legitimate reference. Although the ARI 2016 Report notes a "remarkable level" of reading by Arab peoples, with an average number of books read estimated at 16.08 books per year, only $57 \%$ were books outside the field of study or work. A noted limitation of the report is that it does not account for time spent reading religious texts, likely a significant proportion. Neither does the report provide any information on books read-to or read-by children.

Anecdotal evidence and surveys in several countries suggest low reading rates among Arab children (Iraqi, 1990; Feitelson et al., 1993; and data summarized in the ARI 2016 Report). However, one can expect an increase in the demand for reading to children as literacy rates continue to improve and with an anticipated increase in social mobility usually translating into an increased awareness of the benefits of reading to children. A related analogy is the recent mind shift in how Arab parents perceive and value exercising. In comparison to previous generations, parents are becoming more keen on enrolling their children in sports for its recognized health and social benefits. A similar mind 
shift can be expected with regards to reading to children. Additionally, with improvements in economic mobility, more Arabs will be able to afford buying more books.

\section{CONCLUSION}

The definition of language diglossia has been revisited over the years since its early introduction by Ferguson in 1959. It has expanded to include countries that are bilingual or multilingual. The wikipedia entry 'Lists of diglossic regions' shows 40 nations and regions that feature diglossia. While language diglossia is a more common phenomenon than usually perceived, nonetheless this paper is the first to address the challenges of reading aloud to children in this linguistic context.

Language diglossia in the Arab world is a condition that must be acknowledged. Apart from the academic literature and some examples discussed in this paper, most reports and opinion pieces are silent on the diglossic feature of Arabic and its effect on reading levels in the Arab world. In remaining unacknowledged, the topic is dealt with as a taboo. For instance, the previously mentioned ARI 2016 Report discusses potential reasons for low reading rates and highlights different ways to foster the love of reading from an early age. Yet the report does not mention Arabic diglossia as a possible and critical element in this equation.

To conclude and as asserted in Maamouri (1998), it would be naive to assume that Arabs, even educated Arabs, will start interacting and speaking to one another in $\mathrm{fusHa}$ in their daily life. There has not been any political nor social initiatives to promote such a change. FusHa is unlikely to ever become a mother-tongue and replace the local a'amiya vernaculars. It is thus more realistic and practical to accept the diglossic nature of Arabic, examine its costs and limitations, and try to manage and mitigate them — instead of pretending that Arabic diglossia does not exist.

\section{ACKNOWLEDGMENTS}

The author wishes to thank Professor John Myhill at the University of Haifa, Professor Jeff Siegel at the University of New England and Professor Niloofar Haeri from John Hopkins University for their feedback and helpful comments. The author also thanks all interviewees from the various countries (Egypt, Scotland, Switzerland, \& Germany) for their valuable contributions.

\section{REFERENCES}

[1] Abu-Rabia, S. (2000). Effects of Exposure to Literary Arabic on Reading Comprehension in a Diglossic Situation. Reading and Writing: An Interdisciplinary Journal, 13, 147-157.

[2] Albirini, A. (2016). Modern Arabic Sociolinguistics: Diglossia, Variation, Code-switching, Attitudes and Identity. New York: Routledge, 33-36.

[3] Arab Reading Index-ARI. (2016). UNDP \& Mohammed Bin Rashid Al Maktoum Foundation (MBRF).

[4] Ayari, S. (1996). Diglossia and Illiteracy in the Arab World. Language, Culture and Curriculum, 9, $243-252$.

[5] Baker, L., D. Scher, \& K. Mackler. (1997). Home and Family Influences on Motivations for Reading. Educational Psychologist, 32(2), 69-82.

[6] Bryant, P., L. Bradley, M. Maclean, \& J. Crossland. (1989). Nursery Rhymes, Phonological Skills and Reading. Journal of Child Language, 16(2), 407-428.

[7] Bryant, P. E., M. MacLean, L. L. Bradley \& J. Crossland. (1990). Rhyme and Alliteration, Phoneme Detection, and Learning to Read. Developmental Psychology, 26(3), 429-438.

[8] Bull, T. (1990). Teaching School Beginners to Read and Write in the Vernacular. In Ernst H. Jahr and O. Lorentz (eds.), Troms $\phi$ Linguistics in the Eighties, Oslo: Novus Press, 69-84.

[9] Caldwel, L. (2012). "The Arab Reader and the Myth of Six Minutes." Alakbar English. https://english.alakhbar.com/node/3168 (accessed 15/7/2018).

[10] Clark, C. \& K. Rumbold. (2006). Reading for Pleasure: A Research Overview. London: National Literacy Trust.

[11] DeGraff, M. (2016). Mother Tongue Books in Haiti: The Power of Kreyòl in Learning to Read and in Reading to Learn. Prospects. 46 (3-4), 435-464. https://doi.org/10.1007/s11125-017-9389-6 (accessed 30/9/2018).

[12] Duursma E, M. Augustyn \& B. Zuckerman. (2008). Reading Aloud to Children: The Evidence. Arch Dis Child. 93(7), 554557.

[13] El-Wardani, M. "Book Review: First Novel Written in Colloquial Arabic Republished." Ahram English. http://english.ahram.org.eg/NewsContent/18/62/50815/Books/Review/Book-Review-First-novel-written-in-colloquialArab.aspx (accessed 01/15/2018)).

[14] Eviatar, Z., \& R. Ibrahim. (2014). Why is it Hard to Read Arabic? In E. Saiegh-Haddad \& M. Joshi (Eds.), Handbook of Arabic literacy: Insights and perspectives, 77-98.

[15] Eviatar, Z., \& R. Ibrahim. (2000). Bilingual is as Bilingual Does: Metalinguistic Abilities of Arabic Speaking Children. Applied Psycholinguistics, 21, 451-471.

[16] Feitelson, D., Z. Goldstein, J. Iraqi \& D. L. Share. (1993). Effects of Listening to Story Reading on Aspects of Literacy Acquisition in a Diglossic Situation. Reading Research Quarterly, 28, 71-79.

[17] Ferguson, C. A. (1959). Diglossia. Word. 15, 325-340.

[18] Haeri, N. (2003). Sacred Language, Ordinary People: Dilemmas of Culture and Politics in Egypt. New York: Palgrave MacMillian. 
[19] Haeri, N. (2009). The Elephant in the Room: Language and Literacy in the Arab World. In D. R. Olson \& N. Torrance (Eds.), The Cambridge handbook of literacy. Cambridge: Cambridge University Press.

[20] Hemmati, F., Z. Gholamrezapour \& L. Hessamy. (2015). The Effect of Teachers' Storytelling and Reading Story Aloud on the Listening Comprehension of Iranian EFL Learners. Theory and Practice in Language Studies, 5(7), 1482-1488.

[21] Horst, J. S., K. L. Parsons \& N. M. Bryan. (2011). Get the Story Straight: Contextual Repetition Promotes Word Learning from Storybooks. Frontiers in Psychology, 2, 2-17.

[22] Ibrahim R., \& J. Aharon-Peretz. (2005). Is literary Arabic a Second Language for Native Arab Speakers?: Evidence from a semantic priming study. The Journal of Psycholinguistic Research 34(1), 51-70.

[23] Ibrahim, R. (2009). The Cognitive Basis of Diglossia in Arabic: Evidence from a Repetition Priming Study Within and Between Languages. Psychology Research and Behavior Management, 2, 93-105.

[24] Iraqi, J. (1990). Kriah bifnejalde gan chovah dovre aravit leumat peulot ha 'asharah alternativiot kederech leshipur havanat hanikra umejumanujot lashon [Reading to Arabic-Speaking Kindergarten Children Compared to Alternative Enrichment Activities as a Means of Improving Reading Comprehension and Language Skills]. Unpublished master's thesis, University of Haifa, Haifa.

[25] Khamis-Dakwar, R. (2005). Children's Attitudes Towards the Diglossia Situation in Arabic and its Impact on Learning. Language, Communities, and Education, 1, 75-86.

[26] Lane, H., \& T. L. Wright. (2007). Maximizing the Effectiveness of Reading Aloud. The Reading Teacher, 60(7), 668-675.

[27] Maamouri, M. (1998). Language Education and Human Development: Arabic Diglossia and its Impact on the Quality of Education in the Arab Region. World Bank, Mediterranean Development Forum.

[28] MacLean M, P. Bryant \& L. Bradley. (1987). Rhymes, Nursery Rhymes, and Reading in Early Childhood. Merrill Palmer Q, 33: $255-81$.

[29] Martin, JD., RJ. Martins \& S Naqvi. (2017). Do Arabs Really Read Less? "Cultural Tools" and "More Knowledgeable Others" as Determinants of Book Reliance in Six Arab Countries. International Journal of Communication, 11, 3374 - 3393.

[30] McGee, LM \& J.A. Schickedanz. (2007). Repeated Interactive Read-Alouds in Preschool and Kindergarten. The Reading Teacher, 60(8), 742-751 from the Wiley Online Library. https://doi.org/10.1598/RT.60.8.4 (accessed on 15/9/2018).

[31] Melby-Lervåg, M., SA Lyster \& C. Hulme. (2012). Phonological Skills and their Role in Learning to Read: A Meta-Analytic Review. Psychological Bulletin, 138 (2), 322-352.

[32] Mendelsohn, AL. et al. (2018). Reading Aloud, Play, and Social-Emotional Development. Pediatrics. 141(5):e20173393 pmid:29632254.

[33] Myhill, J. (2014). The Effect of Diglossia on Literacy in Arabic and Other Languages. In E. Saigh-Haddad, \& R. M. Joshi (Eds.), Handbook of Arabic literacy: Insights and perspectives, Springer. New York London 197-223.

[34] Nikolajeva, M. (2012). Guilt, Empathy and the Ethical Potential of Children's Literature. Barnboken - Journal for Children's Literature Research, 35, 1-13. https://www.barnboken.net/index.php/clr/article/view/139/221 (accessed on: 1/9/2018)).

[35] OECD. (2002). Reading for Change: Performance and Engagement Across Countries. Results from PISA 2000. New York: Organization for Economic Cooperation and Development.

[36] Österberg, T. (1961). Bilingualism and the First School Language. Uppsala: Almqvist and Wiksell. Piaget, J. (1952).

[37] Rickford, J. R. (1998). Using the Vernacular to Teach the Standard. Paper presented at the 1998 California State University Long Beach [CSULB] Conference on Ebonics. http://www.johnrickford.com/portals/45/documents/papers/Rickford-20051999-Using-the-Vernacular-to-Teach-the-Standard.pdf (accessed on: 11/10/2018).

[38] Saiegh-Haddad, E., \& B. Spolsky. (2014). Acquiring Literacy in a Diglossic Context: Problems and Prospects, Handbook of Arabic Literacy: Insights and Perspectives, eds E. Saiegh-Haddad and M. Joshi (Dordrecht: Springer), 225-240.

[39] Schiff, R., \& E. Saiegh-Haddad. (2018). Development and Relationships Between Phonological Awareness, Morphological Awareness and Word Reading in Spoken and Standard Arabic. Frontiers in Psychology. https://doi.org/10.3389/fpsyg.2018.00356 (accessed on: 15/9/2018).

[40] Schwartz, L. H., et al. (2009). Barriers to the Broad Dissemination of Creative Works in the Arab World (Vol. 879). Santa Monica, CA: Rand National Defense Research Institute. Retrieved from https://www.rand.org/content/dam/rand/pubs/monographs/2009/RAND_MG879.pdf (accessed on 15/10/2018).

[41] Siegel, Jeff. (2010). Second Dialect Acquisition. Cambridge University Press, UK.

[42] Simpkins, Gary, G. Holt \& C. Simpkins. (1977). Bridge: A Cross-Cultural Reading Program. Boston: Houghton Mifflin.

[43] Tegegne, W. (2015). The Inclusion of Dialects in Education: An Exploration into the Use of Afan Oromo Dialects in Primary Educational Context. International Journal of Language and Linguistics. 3(6): 360-366

[44] Trehearne, M. J., LH Healy, MC Williams, \& JL Moore. (2003). Comprehensive Literacy Resource for Kindergarten Teachers. Vernon Hills, IL: ERA Cuisenaire.

[45] UNDP/Regional Bureau for Arab States. (2003). Arab Human Development Report. Building a Knowledge Society, New York: Oxford University Press. http://hdr.undp.org/sites/default/files/rbas_ahdr2003_en.pdf (accessed on: 15/9/2018).

[46] UNESCO. (2005). The importance of mother tongue-based schooling for educational quality. Paper commissioned for the EFA Global Monitoring Report 2005, The Quality Imperative. http://unesdoc.unesco.org/images/0014/001466/146632e.pdf (accessed on : 15/9/2018).

[47] UNESCO. (2008a). Mother Tongue Matters: Local Language as a Key to Effective Learning. Technical Report. Paris: UNESCO, Paris, France. http://unesdoc.unesco.org/images/0016/001611/161121e.pdf (accessed on : 15/9/2018).

[48] UNESCO. (2008b). Improving the Quality of Mother Tongue-based Literacy and Learning. Case studies from Asia, Africa and South America. UNESCO, Bangkok, Thailand. http://unesdoc.unesco.org/images/0017/001777/177738e.pdf (accessed on : 15/9/2018).

[49] Walter SL., \& DE. Dekker. (2011). Mother Tongue Instruction in Lubuagan: A Case Study from the Philippines. International Review of Education. 57(5-6), 667-683.

[50] World Development Indicators. (2017). World Bank, Washington DC, USA. 


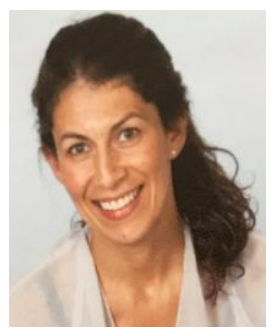

Riham Shendy, was born in Cairo, Egypt. She received her Doctorate Degree (PhD) in Applied Economics from the European University Institute in Florence, Italy and a Master of Science (MSc.) in Quantitative Development Economics from the University of Bristol, UK. From 2008 to 2018, she worked at the World Bank in Washington DC, in the Human Development Network (on Education \& Social Protection) and in the Financial and Private Sector Development Network. Dr. Shendy is a published author in peer reviewed academic journals and has various analytical studies published by international organizations (The World Bank and the International Monetary Fund). 